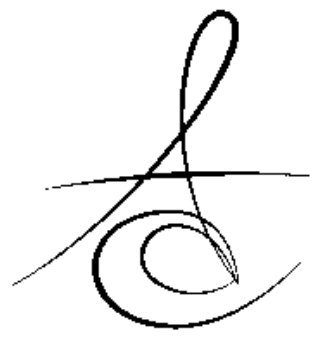

\title{
CAM FİBERLE GÜÇLENDİRİLMİŞ KOMPOZİT VE DOĞAL DİŞ KULLANILARAK ESTETİK KÖPRÜ UYGULAMALARI: İKİ OLGU SUNUMU ${ }^{*}$
}

\author{
AESTHETIC BRIDGES WITH GLASS FIBER AND NATURAL TEETH: \\ TWO CASE REPORTS ${ }^{*}$
}

Dr. Reyhan Şİ̧MAN*

Yrd. Doç. Dr. Mustafa Özay USLU**
Yrd. Doç. Dr. Burak DAYI*

Doç. Dr. Muhammet YALÇIN*

Makale Kodu/Article code: 1765

Makale Gönderilme tarihi: 20.06 .2014

Kabul Tarihi: 22.09.2014

\section{ÖZET}

Günümüz dental pratiğinde hastaların beklentisi restorasyonların mümkün olduğunca kısa zamanda tamamlanması ve estetik olmasının yanı sıra aynı zamanda ekonomik olmasıdır. Bu makalede anterior bölgede periodontal problemleri olan iki dişin çekim sonrası protetik tedavileri anlatılmaktadır. Radyografik, periodontal ve protetik değerlendirmelerden sonra doğal dişlerin cam fiberle güçlendirilmiş kompozit yardımıyla köprü içerisinde kullanılmasına karar verilmiştir. Tedavi prosedüründen 3 ay sonra herhangi bir sıkıntı olmadığı görülmüştür. Ön tek diş kayıpları gibi uygun vaka seçimlerinde fiberle güçlendirilmiş kompozit köprüler hızlı, estetik ve ekonomiktirler. Fakat bu restorasyonlar uzun dönem başarısı açısından takip edilmelidirler.

beyazlatma.

Anahtar kelimeler: cam fiber; diş

\section{GİRISŞ}

Günümüz dental pratiğinde anterior bölge restorasyonlarının hızlı, estetik ve ekonomik olması hastaların ve klinisyenlerin beklentisidir. Dental materyal teknolojisindeki gelişmeler minimal invaziv restorasyonları daha uygulanabilir, estetik ve hızlı hale getirmektedir. Cam fiberle güçlendirilmiş kompozitler (CFGK) kullanılarak minimal diş preparasyonu ile tek seansta bitirilen köprüler bu restorasyonlara örnektir ${ }^{1-}$

3 . Fiber bağlantı materyalleri, rezin matriks içerisinde fiber içeren ve kullanım yelpazesi oldukça geniş olan materyallerdir. ${ }^{4}$ CFGK'lar bölümlü protez restorasyon$\operatorname{larda}^{5}$, kök kanal postları olarak ${ }^{6}$, periodontal splintlerde $^{7,8}$, kompozit veneerlerin güçlendirilmesinde ${ }^{9}$,

\section{ABSTRACT}

In today's dental practice for anterior restorations patients have to wait for more conservative, aestaetic procedures also as quickly and economic as possible. It is described the prosthetic treatment of periodontally destroyed two anterior teeth after extraction at this study. After radiographic, periodontal and prosthetic assessments it was decided to use extracted tooth as pontic with glass fiber to be drawn in the bridge. The clinical situation has been observed successfully after 3 months of treatments. In appropriate cases fiber-reinforced composite bridges are aesthetic, rapid and economic like anterior restoring single tooth missing using the natural tooth. But this restorations should be followed in terms of long-term success.

Keywords: glass fiber; tooth bleaching. ortodontik tedavilerde ${ }^{10}$ başta olmak üzere oldukça geniş alanlarda adeziv teknolojiyle beraber kullanılmaktadır. Anterior tek diş kayıplarında CFGK'lar kullanılarak yapılan köprüler bunlara ilavedir. CFGK köprüler, metal destekli kronlar, implant üstü kronlar, full kaplama kronlar gibi restorasyonların yerine uygulanabilirler ${ }^{2}$ 11,12. Köprü içerisinde gövde (pontik) olarak doğal diş ${ }^{13}$ veya akrilikten dişler ${ }^{11}$ kullanıla- $^{-}$ bilmektedir. Çekilen dişin pontik olarak kullanılması restorasyonun estetik ve hızlı olması açısından çok büyük avantajdır ${ }^{14}$. Ancak canlılığını kaybeden dişlerde oluşabilecek renk değişikliği karşımıza sorun olarak çıkabilmektedir.

Pulpanın canlılı̆ını kaybetmesi sonucunda oluşan renk değişikliğine bakteriyel ve travmatik

*İnönü Üniversitesi, Diş Hekimliği Fakültesi Diş Hastalıkları ve Tedavisi Anabilim Dalı Anabilim Dalı, 44280 Malatya Türkiye

**Inönü Üniversitesi, Diş Hekimliği Fakültesi Periodontoloji Anabilim Dalı, 44280 Malatya Türkiye

${ }^{\prime}$ Bu makalede anlatılan olgu 1, '18. Dünya Dental Travmatoloji Kongresi, 19-21 Haziran 2014,

Istanbul, TÜRKİYE' de poster olarak sunulmuştur.

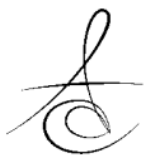


sebeplerle ortaya çıkan hemoliz ile serbestlenen hemosiderin, hemin, hemotidin gibi kan yıkım ürünlerinin sebep olduğu düşünülmektedir ${ }^{15},{ }^{16}$. Dentin kanallarına nüfuz ederek oluşan sarı-kahverengi renklenmeler intrakoronal beyazlatma ile giderilebilir ${ }^{17}$.

$\mathrm{Bu}$ makalede, anterior bölgede periodontal nedenlerle çekilmiş diş boşluklarının çekilmiş dişler kullanılarak CFGK yardımıyla restorasyonu anlatılmaktadır. Hastalar yapılacak olan tedaviler ve başarısızIıklar konusunda bilgilendirilmiş olup "aydınlatılmış onam formu" alınmıştır.

\section{OLGU1}

50 yaşında erkek hasta İnönü Üniversitesi Diş Hekimliği Fakültesine başvurdu. Hastanın radyografik ve klinik muayeneleri sonucunda maxilla sol santral dişinin devital olduğu ve ileri düzeyde periodontal doku kaybı bulunması sebebiyle çekilmesine karar verildi. Hastanın beklentileri göz önünde bulundurularak, protetik ve periodontal açıdan değerlendirmeler yapıldığında çekilecek olan dişin pontik olarak kullanılarak cam fiberle köprü yapılması planlandı. Dişin çekilmesini takiben eklentileri uzaklaştırıldı ve periodontal iyileşme tamamlanıncaya kadar fizyolojik salinde saklandı (Resim-1).

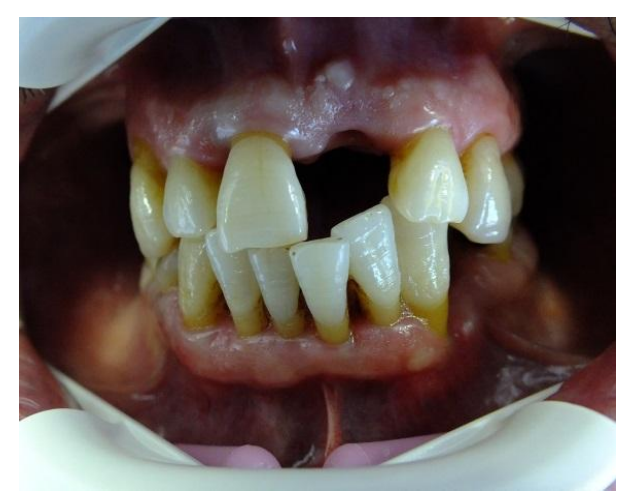

Resim 1. Olgu 1'in tedavi öncesi

Devital dişlerde gözüken renk değişikliği bulunan dişe öncelikli olarak yan dişlerle renk uyumu sağlaması amacıyla intrakoronal bleaching planlandı. Bunun için dişin, dişeti ve insizal seviyeleri uyulmandırarak kök kısmı kesildi. Daha sonra pulpa odası apikaldeki kanal açıklığından 30 numara kanal eğesi ile temizlendi ve sodyum hipoklorit ile yıkandı. Ardından oksijenli su emdirilmiş sodyum perborat kronun içe- risine yerleştirildi, çinkofosfat siman ile kapatıldı, serum fizyolojikte 3 gün bekletildi(Resim-2). Bu süre sonunda dişin yan dişlerle aynı renk tonunu yakaladığı gözlemlendi. Kronun içi serum fizyolojik ile yıkanıp kurutulduktan sonra apikal açıklık mikrohibrit kompozit rezinle (Arabesk N, Voco, Cuxhaven, Almanya) restore edildi.

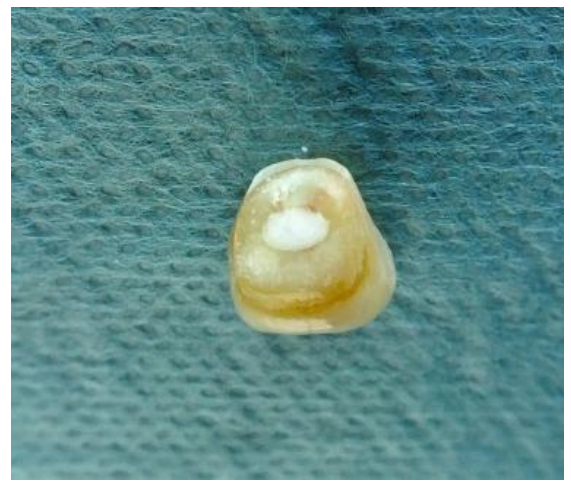

Resim 2. İntrakoronal beyazlatma yapılan diş

Gövdeye dişetine baskı yapmayacak ve temizlenebilecek şekilde form verildi. Çekilmesinden önce anteriorda konumlanan diş için var olan boşluk, dişin mesiodistal genişliğinden dar olduğu için yan yüzeylerden möllendi. Yan dişlerin ve pontik dişin palatinal yüzeylerine cam fiberin geniş̧liği kadar ve yaklaşık $1 \mathrm{~mm}$ derinliğinde oluk açıldı ve kontak yüzeyler aracılığıyla yerine konumlandırıldı. Kontak dişlerin distal yüzeyleri arası mesafe ark formuna uygun şekilde ölçüldü. Bu uzunlukta cam fiber şerit (Grand TEC, Voco, Cuxhaven, Germany) kesildi ve yerleştirilmesi işlemine kadar ışık almamasına dikkat edildi. Pontik diş ve kontak dişlere açılan oluklara \% 37'lik fosforik asit (Pulpdent, Watertown, A.B.D.) uygulandı, 20 sn yıkandı ve 5 sn havayla hafifçe kurutuldu. İki aşamalı self etching adeziv (Clearfil SE Bond, Kuraray, Okayam, Japonya) üretici firma talimatlarına göre uygulandı.

İnce tabaka halinde akıcı kompozit uygulanan oluklara presel ve ağız spatülü yardımıyla cam fiber şerit ark formuna uygun şekilde yerleştirildi ve her açıdan 20 sn boyunca ışınlandı. Ardından mikrohibrit kompozitle restore edildi ve ağız ortamı ile ilişkisi tamamen kapatıldı. Oklüzyon kontrol edildi ve primer kontaklar elimine edildi. Son olarak polisajı yapıldıktan (Sof-Lex, 3M ESPE, Seefeld, Almanya) sonra tedavi sonlandırıldı (Resim-3). 

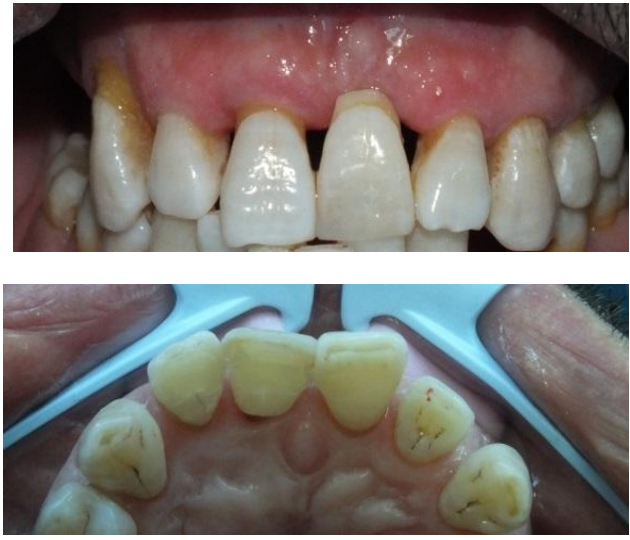

Resim 3.Olgu1 tedavi sonrası görüntü

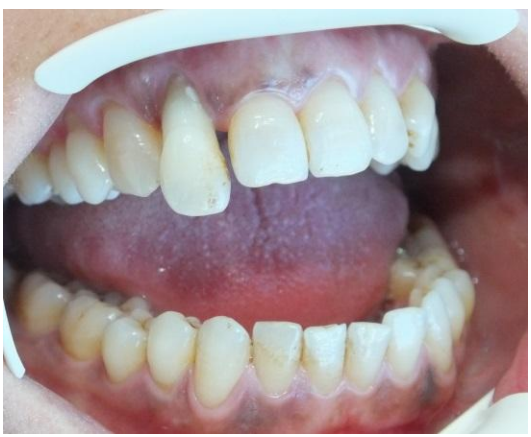

Resim 4. Olgu 2'nin tedavi öncesi

\section{OLGU 2}

45 yaşında bayan hasta İnönü Üniversitesi Diş Hekimliği Fakültesine başvurdu. Hastanın radyografik ve klinik muayeneleri sonucunda maxilla sağ lateral dişinin devital olduğu ve ileri düzeyde periodontal doku kaybı bulunması sebebiyle çekilmesine karar verildi (Resim-4). Hastanın beklentileri göz önünde bulundurularak, protetik ve periodontal açıdan değerlendirmeler yapıldığında çekilecek olan dişin pontik olarak kullanılarak cam fiberle köprü yapılması planlandı. Hasta muhtemel başarısızlıklar hakkında bilgilendirildi. Dişin çekilmesini takiben eklentileri uzaklaştırıldı ve periodontal iyileşme tamamlanıncaya kadar fizyolojik salinde saklandı. Dişin kökünün kesilmesi ve pulpa artıklarını uzaklaştırmasından sonra açıklık mikrohibrit kompozit rezinle şekillendirildi. Yan dişlerin ve pontik dişin palatinal yüzeylerine cam fiberin genişliği kadar ve yaklaşık $1 \mathrm{~mm}$ derinliğinde oluk açıldı ve asit uygulaması yapılmadan gerekli kontrol ve düzeltmelerin yapılabilmesi için bonding rezinle yerine yerleştirildi.

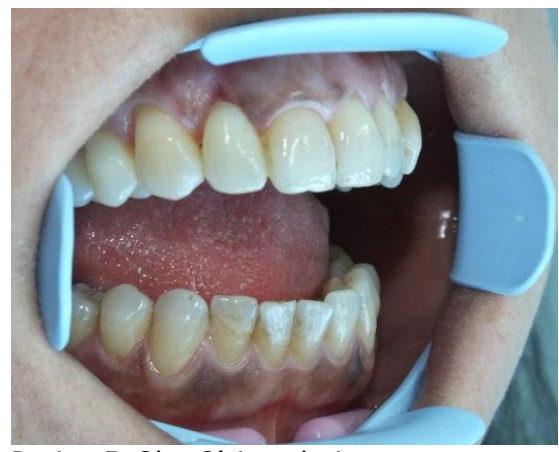

Resim 5. Olgu 2'nin tedavi sonrası

Kontak dişlerin distal yüzeyleri arası mesafe ark formuna uygun şekilde ölçüldü. Bu uzunlukta cam fiber şerit (Grand TEC, Voco, Cuxhaven, Almanya) kesildi ve yerleştirilmesi işlemine kadar ışık almamasına dikkat edildi. Cam fiber şeritin yerleştirme işlemi olgu $1^{\prime}$ de anlatıldığı gibi gerçekleştirildi. Ardından mikrohibrit kompozitle restore edildi ve ağız ortamı ile ilişkisi tamamen kapatıldı. Oklüzyon kontrol edildi ve primer kontaklar elimine edildi. Ardından polisajı yapıldı (Sof-Lex, 3M ESPE, Seefeld, Almanya) (Resim5).

Maxilla sağ lateral dişin çekim bölgesinde meydana gelen diş eti konturu düzensizliğinin düzeltilmesi için bağ dokusu grefti uygulandı. Palatinal bölgeden insizyonlar gerçekleştirilip alınan bağ dokusu yarım kalınlık flebe sutura edildi ve flep fiber köprü altına uyumlandırılarak kapatıldı. Cerrahi sonrası periodontal pat konuldu ve antienflamatuar ilaç ve gargara reçete edildi. Suturların ve patın alınmasının ardından yeterli dişeti kalınlığının sağlandığı gözlemlendi (Resim-6).

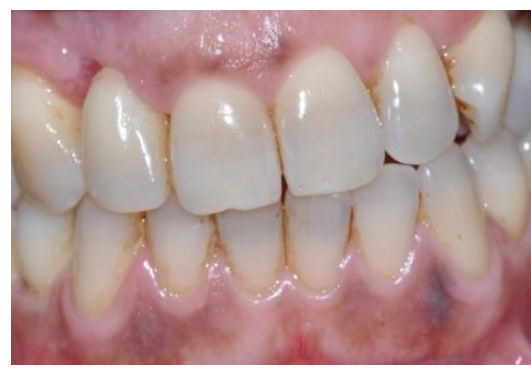

Resim 6. Olgu 2'nin bağ dokusu grefti yerleştirmesinden 1 ay sonraki görüntüsü

\section{TARTIŞMA}

Anterior bölgede yer alan köprülerde estetik gereksinimler çok önemlidir ${ }^{18}$. Bu beklenti diş

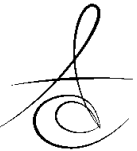


hekimlerini hızlı ve koruyucu çözümler üretmeye yönlendirmektedir. Anterior bölgede oluşan tek diş eksikliklerinin restorasyonlarında tedavi seçenekleri konvansiyonel metal destekli veya full seramik köprü, tek diş implant veya resin tutuculu köprülerdir. Tüm şartlar göz önünde bulundurulup hastaya en uygun tedavi seçeneği sunulmalıdır. Bu makalede hastaların kendi dişleri CFGK yardımılla pontik olarak kullanılarak ön diş tek diş boşlukları restore edilmesi anlatılmıştır. Bu seçimde hastaların sosyo ekonomik düzeyinin yanı sıra implant için gerekli kemik desteğinin bulunmaması ve kron köprü restorasyonuyla kıyasla çok daha konservatif ve estetik olması ${ }^{14}$ etkin olmuştur.

Son yıllarda CFGK' lardaki gelişmeler artmaktadır. Bu gelişmeler yeterli sağlamlığa ve klinik kullanıma sahip inley destekli köprülerin yapılmasına olanak sağlamışlardır ${ }^{19}$. Tek diş kayıplarında metal içermemeleri, estetik oluşları, yeterli bağlanma dayanımları bulunması nedeniyle ön diş restorasyonlarda da kullanımları yaygınlaşmaktadır ${ }^{20}$. CFGK'lerin, geleneksel kompozit veya seramiklerle karşılaştırıldı̆ında gelişmiş mekanik özellikleri, yüksek doldurucu içerikleri ve optimum polimerizasyon işlemleri vardır ${ }^{21}$. CFGK iyi esneme modülleri ve diğer fiziksel özelliklerinin ${ }^{22}$ yanı sıra metal destekli protezlere göre daha translüsent olduğu, opak maskelemeye intiyaç duymadığı için estetik üstünlükleri vardır. Bu köprüler indirek yapılabildiğij $^{23}$ gibi direk de uygulanabilirler ${ }^{20}$. Bizim vakamızda pontiğe servikal bölgede modifiye ridge lap formu verilmiştir. Anterior bölgede pontiğe modifiye ridge lap şeklin verilmesi iyi polisajlanabilme, temizlenebilme ve düzgün yüzey oluşma avantajları sağlamaktadır. ${ }^{24}$. Ayrıca dişlere açılan sulkusların görevi tutuculuğu artırmanın yanısıra oklüzyonda fiber için gerekli yer sağlamaktır ve bunun için ortalama 1$1,5 \mathrm{~mm}$ derinlikte sulkuslar yeterlidir ${ }^{25}$.

CFGK köprülerde ortalama 42 ile 96 ay arasında başarı rapor edilmiştir ${ }^{26}{ }^{27}$. Bu süre klinik kullanım için kabul edilebilir bir süredir. Soares ve arkadaşları CFGK köprü uygulamasını posterior bölgede kullanmış ve başarıı sonuç almışıı ${ }^{28}$. Ayrıca Frese ve arkadaşlarının yaptığı 4.5 yıllık takip çalışmasında anterior bölgede uygulanan CFGK' in \% 86.5 inin başarılı olduğu ve anterior bölge tedavileri arasında güvenilir bir yer aldığı belirtilmiştir ${ }^{29}$. Ancak uygulama esnasinda restorasyonun mekanik adaptasyonuna ve adeziv sistemin teknik hassasiyetine dikkat edildiğinde bu başarı daha da artabiliir ${ }^{13}$. Başka bir çalışmada ise pontik cinsi ve kalınlığının yük taşıma kapasitesini değiştirdiği, ince kalınlıklarda kompozit ve polimer pontiklerin, daha geniş kalınlıklarda ise seramik pontiklerin daha fazla yük taşııığı gösterilmiştir ${ }^{30}$.

Normal devital bleaching prosedüründe pulpa odasına koronal bölgeden girilerek beyazlatma ajanı yerleştirilirken bizim olgumuzda pontik olarak kullanılan doğal diş̧in kök kısmı kesildiği için beyazlatma ajanı apikal açıklıktan yerleştirilmiş kronal bölgede fazladan madde kaybı yapılmamıştır.

\section{SONUÇLAR}

1. CFGK köprü uygulamaları beraberinde başka estetik uygulamaların da yapılmasına olanak tanır. Çekilmiş dişlerin kullanılması, beyazlatma veya pembe estetik gibi işlemlerinde rahatça yapılabilmesini sağlar. En az işlemle en kısa zamanda mükemmel sonuçlar elde edilebilir.

2. Ön tek diş kayıpları gibi uygun vaka seçimlerinde fiberle güçlendirilmiş kompozit köprüler hızlı, estetik ve ekonomiktirler. Fakat bu rastorasyonlar uzun dönem başarısı açısından takip edilmelidirler.

\section{KAYNAKLAR}

1. Chafaie A, Portier R. Anterior fiber-reinforced composite resin bridge: a case report. Pediatr Dent 2004;26:530-4.

2. Khetarpal A, Talwar S, Verma M. Creating a SingleVisit, Fibre-Reinforced, Composite Resin Bridge by Using a Natural Tooth Pontic: A Viable Alternative to a PFM Bridge. J Clin Diagn Res 2013;7:772-5.

3. Chafaie A, Dahan S, Le Gall M. Fiber-reinforced composite anterior bridge in pediatric traumatology: clinical considerations. Int Orthod 2013;11:445-56.

4. Freilich MA, Meiers JC, Duncan JP, Goldberg AJ. Fiber reinforced composites in clinical dentistry 2000; Quintessence Pub. Co. Inc, Illinois

5. Ahlstrand WM, Finger WJ. Direct and indirect fiberreinforced fixed partial dentures: case reports. Quintessence Int 2002;33:359-65.

6. Mannocci F, Ferrari M, Watson TF. Intermittent loading of teeth restored using quartz fiber, carbon-quartz fiber, and zirconium dioxide ceramic root canal posts. J Adhes Dent 1999;1:153-8.

7. Sekhar LC, Koganti VP, Shankar BR, Gopinath A. A comparative study of temporary splints: bonded 
polyethylene fiber reinforcement ribbon and stainless steel wire + composite resin splint in the treatment of chronic periodontitis. J Contemp Dent Pract 2011;12:343-9.

8. Kumbuloglu O, Aksoy G, User A. Rehabilitation of advanced periodontal problems by using a combination of a glass fiber-reinforced composite resin bridge and splint. J Adhes Dent 2008;10:6770.

9. Vallittu PK. Use of woven glass fibres to reinforce a composite veneer. A fracture resistance and acoustic emission study. J Oral Rehabil 2002;29:423-9.

10. Rantala LI, Lastumaki TM, Peltomaki T, Vallittu PK. Fatigue resistance of removable orthodontic appliance reinforced with glass fibre weave. J Oral Rehabil 2003;30:501-6.

11. Vallittu PK, Sevelius C. Resin-bonded, glass fiberreinforced composite fixed partial dentures: a clinical study. J Prosthet Dent 2000;84:413-8.

12. Monaco C, Ferrari M, Miceli GP, Scotti R. Clinical evaluation of fiber-reinforced composite inlay FPDs. Int J Prosthodont 2003;16:319-25.

13. Bagis B, Satiroglu I, Korkmaz FM, Ates SM. Rehabilitation of an extracted anterior tooth space using fiber-reinforced composite and the natural tooth. Dent Traumatol 2010;26:191-4.

14. Belli S, Ozer F. A simple method for single anterior tooth replacement. J Adhes Dent 2000;2(1):67-70.

15. Guldener PHA, Langeland K. Endodontologie. 3rd ed. Stuttgard: Thieme; 1993.

16. Attin T, Paque F, Ajam F, Lennon AM. Review of the current status of tooth whitening with the walking bleach technique. International Endodontic Journal 2003;36:313-29.

17. Rostein I. Tooth discoloration and bleaching. In: Ingle JI, Bakland LK, eds. End-odontics. 5th ed. Hamilton, Ontario, Canada: BC Decker Inc, 2002:845- 60.

18. Zaimoglu A, Can G. Sabit Protezler. 1. BasIm. Ankara: Ankara Üniversitesi Basımevi; 2004. s. 222-5.

19. Karaalioğlu OF, Aladağ, Lİ. Cam fiber ile güçlendirilmiş kompozit reköprü restorasyonu-vaka raporu Atatürk Üniv Diş Hek Fak Derg 2009; 19(2): 111-4.

20. Garoushi S, Lassila L, Vallittu PK. Resin-bonded fiber-reinforced composite for direct replacement of missing anterior teeth: a clinical report. Int J Dent 2011;2011:845420.

21. Cho L, Song H, Koak J, Heo S. Marginal accuracy and fracture strength of ceromer/fiber-reinforced composite crowns: effect of variations in preparation design. J Prosthet Dent 2002; 88:38895.

22. Freilich MA, Karmaker AC, Burstone CJ, Goldberg AJ. Flexure strength and handling characteristics of fiber-reinforced composites used in prosthodontics. J Dent Res 1997;76:18

23. Kharade P, Sharma S, Banerjee A, Gupta T. Indirect resin-bonded fiber-reinforced composite anterior bridge: A case report. Gen Dent 2012;60:e170-2.

24. Stein RS. Pontic-residual ridge relationship: a research report. J Prosthet Dent 1966;16:251-85.

25. Strassler HE, Serio FG: Stabilization of the natural dentition in periodontal cases using adhesive materials. Periodontal Insights 1997; July: 4-10.

26. Karbhari VM, Rudo DN, Strassler HE. The development and clinical use of lenowoven UHMWPE ribbon in dentistry. Proceedings of the Society for Biomaterials. (abstract issue), 29:15 (abstract no. 529), 2003.

27. Freilich MA, Meiers JC, Duncan JP, Eckrote KA, Goldberg AJ. Clinical evaluation of fiber-reinforced fixed bridges. J Am Dent Assoc 2002;133:1524-34; quiz 40-1.

28. Soares CJ, Barreto BC, Santos-Filho PC, Raposo LH, Martins LR. Using a fiber-reinforced composite fixed partial denture to restore a missing posterior tooth: a case report. Gen Dent 2013;61:61-5.

29. Frese C, Schiller P, Staehle HJ, Wolff D. Fiberreinforced composite fixed dental prostheses in the anterior area: A 4.5-year follow-up. J Prosthet Dent 2014.

30. Perea L, Matinlinna JP, Tolvanen M, Lassila LV, Vallittu PK. Fiber-reinforced Composite Fixed Dental Prostheses with Various Pontics. J Adhes Dent 2013.
Yazışma Adresi
Dr. Reyhan Şİ̧̧MAN
Inönü Üniversitesi,
Diş Hekimliği Fakültesi
Diş Hastalıkları ve Tedavisi Anabilim Dalı,
44280 Malatya Türkiye
Fax: +90-442-3411107
e-mail: dtreyhan@hotmail.com

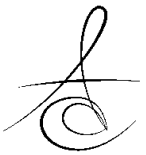

